\title{
Platelet Carbonic Anhydrase II, a Forgotten Enzyme, May Be Responsible for Aspirin Resistance
}

\author{
M. Jakubowski, ${ }^{1}$ J. Dębski, ${ }^{2}$ E. Szahidewicz-Krupska, ${ }^{1}$ A. Turek-Jakubowska, ${ }^{1}$ J. Gawryś, ${ }^{1}$ \\ K. Gawryś, ${ }^{1}$ R. Skomro, ${ }^{3}$ A. Derkacz, ${ }^{1}$ and A. Doroszko ${ }^{1}$ \\ ${ }^{1}$ Department of Internal Medicine, Occupational Diseases and Hypertension, Wroclaw Medical University, Wroclaw, Poland \\ ${ }^{2}$ Institute of Biochemistry and Biophysics, Polish Academy of Sciences, Warszawa, Poland \\ ${ }^{3}$ Division of Respiratory, Critical Care and Sleep Medicine, Department of Medicine, University of Saskatchewan, Saskatoon, \\ SK, Canada
}

Correspondence should be addressed to A. Doroszko; adrian.doroszko@umed.wroc.pl

Received 22 June 2017; Revised 22 August 2017; Accepted 6 September 2017; Published 27 September 2017

Academic Editor: Valentina Pallottini

Copyright ( $\odot 2017$ M. Jakubowski et al. This is an open access article distributed under the Creative Commons Attribution License, which permits unrestricted use, distribution, and reproduction in any medium, provided the original work is properly cited.

Background. Thromboembolic events constitute a major health problem, despite the steadily expanding arsenal of antiplatelet drugs. Hence, there is still a need to optimize the antiplatelet therapy. Objectives. The aim of our study was to verify a hypothesis that there are no differences in platelet proteome between two groups of healthy people representing different acetylsalicylic acid (aspirin) responses as assessed by the liquid chromatography/mass spectrometry (LC/MS) technique. Patients/Methods. A total of 61 healthy volunteers were recruited for the study. Physical examination and blood collection were followed by platelet-rich plasma aggregation assays and platelet separation for proteomic LC/MS analysis. Arachidonic acid(AA-) induced aggregation (in the presence of aspirin) allowed to divide study participants into two groups aspirin-resistant (AR) and aspirin-sensitive (AS) ones. Subsequently, platelet proteome was compared in groups using the LC/MS analysis. Results. The LC/MS analysis of platelet proteome between groups revealed that out of all identified proteins, the only discriminatory protein, affecting aspirin responsiveness, is platelet carbonic anhydrase II (CA II). Conclusions. CA II is a platelet function modulator and should be taken into consideration as a cardiovascular event risk factor or therapeutic target.

\section{Introduction}

Despite the steadily expanding arsenal of antiplatelet agents, thromboembolic events are still common in clinical practice [1]. Acetylsalicylic acid (ASA, aspirin), widely used in the high-cardiovascular-risk population, is in many cases ineffective. This phenomenon, called aspirin resistance (AR), remains still an important clinical problem. Its pathogenesis and incidence persist the subject of numerous studies and controversies [2-5]. ASA exerts its anti-aggregatory effect mostly by inhibiting the platelet COX-1 and subsequently thromboxane formation from the arachidonic acid cascade. Aspirin resistance, at molecular level, may be attributed, that is, to changes in efficacy of COX-1 acetylating by ASA [6]. Studies focusing on the AR phenomenon defined in this way do not precise the time frame between the last aspirin dose and blood sampling [6, 7].

On the other hand, ASA treatment failure may result from factors that are COX-1 independent, including noncompliance [7], increased platelet turnover [2], and platelet COX-1 resynthesis [8], and factors increasing platelet reactivity. Up to date, there are several papers describing factors, which expression increases during ASA therapy and which are associated with the AR phenomenon. Studies by Voora et al. show that following 4 weeks of ASA treatment ( $325 \mathrm{mg} /$ day), the platelet sensitivity to ADP, epinephrine, and collagen significantly increases despite sufficient COX inhibition [9]. The authors introduced a term "aspirin response signature," which is a set of coexpressed genes assessed in peripheral blood during ASA treatment that are 
strongly correlated with COX1-independent platelet function and represent increased risk of myocardial infarction and death [10].

Furthermore, Massimi et al. proved that ASA in both in vitro cell lines $[11,12]$ and in vivo platelets (over two months of treatment) enhances expression of the multidrug resistance protein 4 (MRP4), high concentration of which is associated with greater TxB2 synthesis, and subsequently more intense collagen-induced aggregation [13]. The platelet MRP4 might be also induced by other nonsteroidal antiinflammatory drugs [14]. The presence of factor enhancing the "on aspirin" arachidonic acid induced aggregation (exclusively limited to COX-1 pathway) verified by Floyd et al. who have found that truly resistant subjects are characterized by higher platelet expression of glycoprotein IIIa (GPIIIa) following 28 days of ASA treatment (300 mg/d) [15].

Noteworthy, in some studies there is observed interindividual heterogeneity in platelet in vitro response to low ASA doses [15]. The question arises if, beside inducible factors limiting ASA chronic treatment, there are constitutively present factors limiting platelet responsiveness to ASA at baseline.

A novel approach - the use of techniques analyzing the functional proteome-should allow to define factors determining individual variability of platelet activity. By analyzing the platelet proteome in patients with ASA resistance, we intended to define novel mechanisms limiting platelet responsiveness to acetylsalicylic acid.

Therefore, the aim of the study was to verify the hypothesis regarding the lack of differences in platelet proteome between groups with different sensitivities to aspirin, as assessed by the liquid chromatography/mass apectrometry (LC/MS) technique.

\section{Material and Methods}

2.1. Bioethics Statement. All experiments were conducted and approved in accordance with the guidelines of the local Bioethics Committee and adhered to the principles of the Declaration of Helsinki and Title 45, U.S. Code of Federal Regulations, Part 46, Protection of Human Subjects (revised: November 13, 2001; effective: December 13, 2001). All participants provided their written consent to participate in the study. The written consent forms had been previously approved by the ethics committee.

2.2. Recruitment and Examination. A total of 61 clinically healthy volunteers (at the age of 18-60 years) were enrolled to the study. Exclusion criteria were diabetes, hypertension, chronic and acute inflammatory diseases, mental disorders, malignancies, allergy to nonsteroidal anti-inflammatory drugs (NSAID), or the use of NSAID one week prior to the examination.

All participants underwent standard physical examination, and their blood was collected nontraumatically from the antecubital vein using a Sarstedt S-Monovette ${ }^{\circledR}$ system (Sarstedt AG \& Co., Nümbrecht, Germany). Study participants were divided into two groups according to the aspirin response (the presence of platelet aggregation in response to arachidonic acid (AA) following an in vitro incubation with a fixed dose of ASA) (Figure 1).

At first, baseline characteristics of the groups were compared: then, the presence of differences in the blood test results (including cardiovascular risk factors and markers of endothelial and platelet function) was verified, which was subsequently followed by an analysis of differences in platelet proteome between aspirin-resistant (AR) and aspirinsensitive (AS) subjects.

2.3. Aggregometry. Aggregation was performed in platelet-rich plasma using a 2-channel optical aggregometer (Chrono-log 490-2D, Chrono-Log, Pennsylvania, USA), and platelet response to arachidonic acid with and without aspirin was tested simultaneously. The aggregation discriminating the groups was performed using arachidonic acid (at $1 \mathrm{mM}$ of final concentration) added to platelet-rich plasma (PRP) in 5 minutes following its incubation with acetylsalicylic acid (final concentration $30 \mu \mathrm{M}$, for 5 minutes). Since agonist application, the reaction progress was recorded for 6 minutes using dedicated software (Aggro/link, ChronoLog, Pennsylvania, USA). The aggregation results were calculated according to the manufacturer's instruction by the Chronolog Software and are expressed as the area under the aggregation curve (AUC), which equals zero for no aggregation was calculated during the course of aggregation protocol (from agonist addition until the termination of aggregation at the end of the sixth minute).

A complete inhibition of the aggregation by ASA was the criterion for diagnosing aspirin resistance. The experiment was performed at a constant temperature of $37^{\circ} \mathrm{C}$.

Also, control aggregations were performed using other final concentrations of agonist and antagonist: AA $0.5 \mathrm{mM}$ and Lys-ASA $0.03 \mathrm{mM}$ and AA $1 \mathrm{mM}$ and Lys-ASA $0.05 \mathrm{mM}$. Additionally, in cases when Lys-ASA at $0.05 \mathrm{mM}$ of final concentration was insufficient to prevent the AAinduced aggregation, a test with Lys-ASA at $0.1 \mathrm{mM}$ of final concentration and $\mathrm{AA}$ at $1 \mathrm{mM}$ of constant concentration was performed.

2.4. Platelet Preparation for Proteomic Analyzes. The whole blood was supplemented with prostacyclin $\left(\mathrm{PGI}_{2}\right)$ at the final concentration of $0.06 \mu \mathrm{g} / \mathrm{ml}$, and centrifuged for 20 minutes at $230 \times \mathrm{g}$ at $21^{\circ} \mathrm{C}$ in order to obtain PRP. Subsequently, PRP was supplemented with $\mathrm{PGI}_{2}$ (final concentration $0.3 \mu \mathrm{g} / \mathrm{ml}$ ) and centrifuged for 10 minutes at $1000 \times \mathrm{g}$ at $21^{\circ} \mathrm{C}$. The plasma was discarded, and the platelet pellet was gently washed three times with $1 \mathrm{ml}$ of TyrodesHEPES buffer pH 7.4 ml. Rinsed platelets were suspended in $4 \mathrm{ml}$ of Tyrodes-HEPES buffer $\mathrm{pH} 7.4$ supplemented with $\mathrm{CaCl}_{2}$ (final concentration $1 \mathrm{mM}$ ). Resulted suspension was immediately analyzed for platelet count and contamination with WBC i RBC (Sysmex device, Clinical Laboratories Department, University Hospital, Wrocław, Poland).

The pure PLT suspension was adjusted with TyrodesHEPES buffer $\mathrm{pH} 7.4$ containing $\mathrm{CaCl}_{2}$ to a final concentration of $2.5 \times 10^{8} / \mathrm{ml}$. Samples containing platelets in amounts of $2.5 \times 10^{8}$ and $7.5 \times 10^{8}$ cells were preserved for further proteomic analysis. The samples were obtained 


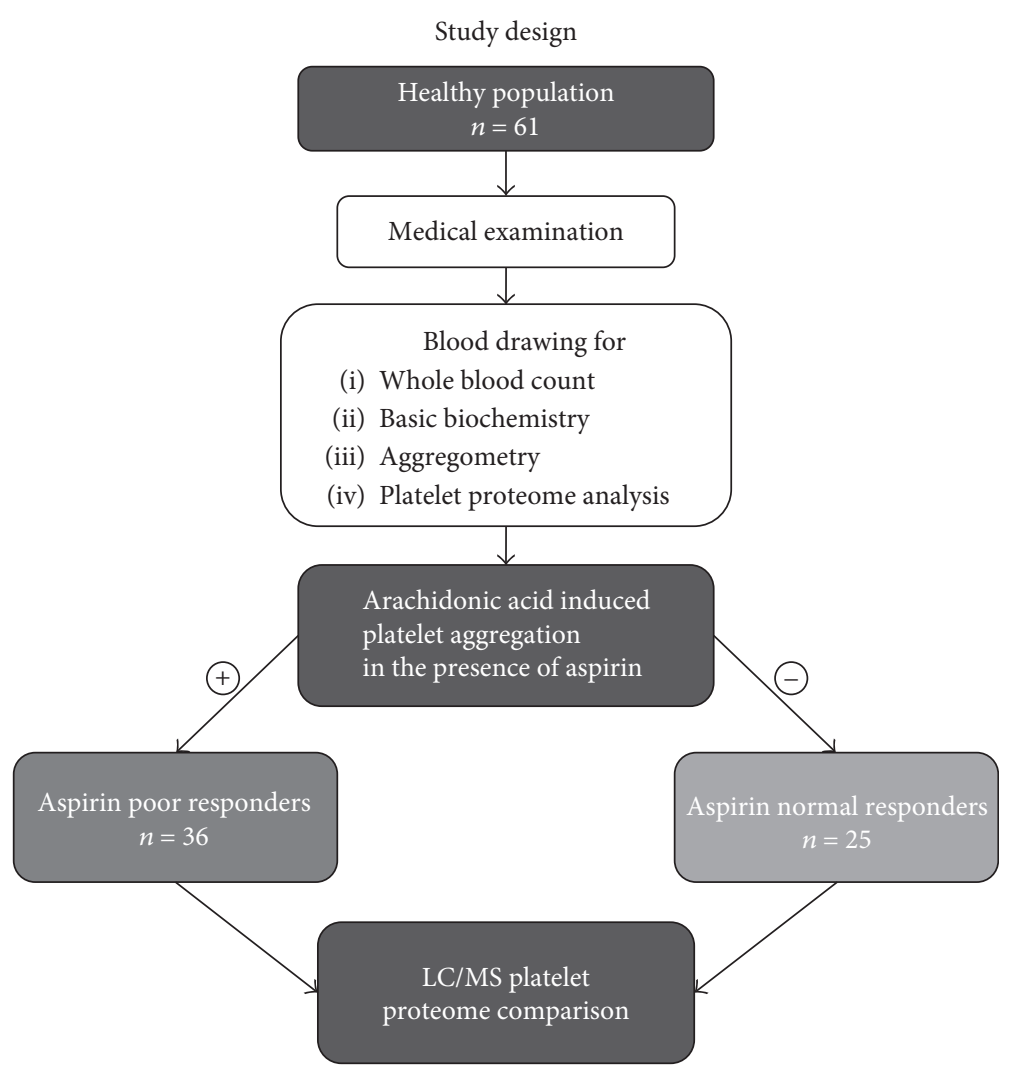

Figure 1: Study protocol.

by centrifugation of the suspension of known concentration for $5 \mathrm{~min}, 10000 \times \mathrm{g}$ at $4^{\circ} \mathrm{C}$, and stored at $-80^{\circ} \mathrm{C}$ until proteomic analyses.

Aggregations of separated platelets in response to collagen were also performed. A $500 \mu \mathrm{l}$ of platelet suspension $\left(2.5 \times 10^{8} / \mathrm{ml}\right)$ was substituted with collagen (final concentration $5 \mu \mathrm{g} / \mathrm{ml}$ ), and aggregation was conducted for $6 \mathrm{~min}$ and then immediately stopped by placing cuvettes on ice. Pellet and supernatant were separated by consecutive centrifugation, for $5 \mathrm{~min}$ at $10000 \times \mathrm{g}$ and $4^{\circ} \mathrm{C}$. Obtained material was stored till proteomic analyses at $-80^{\circ} \mathrm{C}$.

2.5. Liquid Chromatography/Mass Spectrometry (LC/MS). All used reagents were from Sigma, unless otherwise specified. Platelet proteins were extracted by incubation of platelets in $1 \%$ sodium deoxycholate, $10 \mathrm{mM}$ Tris $\mathrm{HCl} \mathrm{pH} 8$, with the addition of $0.1 \%$ sodium dodecyl sulfate, followed by sonication, and clarified by centrifugation (Eppendorf Minispin, $10 \mathrm{~min}, 12100 \mathrm{~g}$ ). Protein concentration was measured, and proteins were reduced with $50 \mathrm{mM}$ phosphine, alkylated with $200 \mathrm{mM}$ thiosulfonate, and digested overnight at $37^{\circ} \mathrm{C}$ with modified trypsin (V5111, Promega). The digestion reaction was quenched by the addition of $2 \mu \mathrm{l}$ of $10 \%$ trifluoroacetic acid. The concentration of the digested peptides was determined by the Direct Detect Method by Millipore. Sample volume corresponding to $5 \mu \mathrm{g}$ of digested platelet proteins was subjected for proteomic processing, during which peptides were separated by nano-HPLC C-18 column (nanoACQUITY Symmetry ${ }^{\circledR}$ BEH C18, Waters 186003545) using an acetonitrile gradient ( $5-35 \%$ in $180 \mathrm{~min}$ ) in the presence of $0.1 \%$ formic acid with a flow rate of $250 \mathrm{nl} / \mathrm{min}$. The chromatographic column outlet was directly coupled to the ESI-LTQ-Orbitrap Velos mass spectrometer (Thermo Electron Corp., San Jose, CA, USA) and was operating in the MS (the measurement of the masses of the peptides) and MS/MS (peptides fragmentation) in data-dependent acquisition. The raw data was processed using Mascot Distiller followed by analysis with Mascot software (Matrix Science), using database Swiss-Prot, with taxonomy restricted to Homo sapiens [16]. Peptides with a Mascot score exceeding the threshold value corresponding to $<1 \%$ FDR were considered to be positively identified. Label-free quantization was performed as described previously [17]. The lists of identified proteins were analyzed using Diffprot software [18].

2.6. Endothelial and Platelet Activation Markers. Plasma concentrations of sP-selectin/CD62P and PAI-1 were determined by a sandwich enzyme immunoassay technique, using commercial ELISA kits (Cat: BBE6 and DSE100, R\&D Systems Europe Ltd., UK) with a sensitivity of $0.5 \mathrm{ng} / \mathrm{ml}$, according to the manufacturer's instructions. The optical density 450/620 nm was measured with a BioTek Absorbance Microplate Reader with software Gen5. The coefficient of variation $(\mathrm{CV})$ intra-assay $\% \mathrm{CV}$ was calculated as the ratio of the pooled standard deviation from all samples (each was analyzed in triplicate) and the overall mean and then multiplied by 100 . Interassay $\% \mathrm{CV}$ refers to assay-to-assay consistency that was calculated using the pooled standard deviation 
TABLE 1: Baseline demographic characteristics and biochemical stratification of cardiovascular risk in subgroups separated according to the ASA response.

\begin{tabular}{|c|c|c|c|}
\hline - & Aspirin resistant $(\mathrm{AR})($ mean $\pm \mathrm{SEM})$ & Aspirin sensitive $(\mathrm{AS})($ mean $\pm \mathrm{SEM})$ & $p$ \\
\hline$N$ & $36-$ & $25-$ & \\
\hline Women [\%] & $22(61 \%)$ & $5(20 \%)$ & \\
\hline Age $[y]$ & $30.28 \pm 1.74$ & $29.16 \pm 1.81$ & 0.41 \\
\hline BMI $\left[\mathrm{kg} / \mathrm{m}^{2}\right]$ & $22.87 \pm 0.61$ & $24.11 \pm 0.67$ & 0.10 \\
\hline $\mathrm{WBC}[\mathrm{k} / \mu \mathrm{l}]$ & $5.77 \pm 0.22$ & $5.66 \pm 0.26$ & 0.80 \\
\hline $\mathrm{RBC}[\mathrm{mln} / \mu \mathrm{l}]$ & $4.68 \pm 0.08$ & $4.94 \pm 0.09$ & 0.02 \\
\hline Hemoglobin [g/dl] & $13.96 \pm 0.25$ & $14.74 \pm 0.30$ & 0.03 \\
\hline Hematocrit [\%] & $40.12 \pm 0.64$ & $42.12 \pm 0.69$ & 0.05 \\
\hline $\operatorname{MCV}[\mathrm{fl}]$ & $85.89 \pm 0.51$ & $86.10 \pm 0.67$ & 0.82 \\
\hline $\mathrm{MCH}[\mathrm{pg}]$ & $29.86 \pm 0.20$ & $30.09 \pm 0.35$ & 0.46 \\
\hline $\mathrm{MCHC}[\mathrm{g} / \mathrm{dl}]$ & $34.77 \pm 0.15$ & $34.95 \pm 0.22$ & 0.54 \\
\hline $\operatorname{PLT}[\mathrm{k} / \mu \mathrm{l}]$ & $236.72 \pm 9.98$ & $213.76 \pm 9.32$ & 0.12 \\
\hline PDW [fl] & $13.79 \pm 0.37$ & $13.55 \pm 0.46$ & 0.50 \\
\hline Glucose $[\mathrm{mg} / \mathrm{dl}]$ & $83.39 \pm 1.07$ & $88.52 \pm 2.06$ & 0.03 \\
\hline Creatinine $[\mathrm{mg} / \mathrm{dl}]$ & $0.96 \pm 0.02$ & $1.11 \pm 0.03$ & $<0.001$ \\
\hline eGFR $[\mathrm{ml} / \mathrm{min}]$ & $82.78 \pm 1.51$ & $79.76 \pm 1.84$ & 0.25 \\
\hline Uric acid [mg/dl] & $7.25 \pm 1.68$ & $5.49 \pm 0.22$ & 0.18 \\
\hline hsCRP [mg/l] & $1.77 \pm 0.44$ & $0.74 \pm 0.18$ & 0.06 \\
\hline Total cholesterol [mg/dl] & $179.97 \pm 6.16$ & $190.52 \pm 6.38$ & 0.35 \\
\hline $\mathrm{HDL}[\mathrm{mg} / \mathrm{dl}]$ & $54.25 \pm 1.89$ & $53.20 \pm 1.87$ & 0.89 \\
\hline $\mathrm{LDL}[\mathrm{mg} / \mathrm{dl}]$ & $105.72 \pm 5.62$ & $115.96 \pm 5.47$ & 0.26 \\
\hline Triglycerides [mg/dl] & $90.42 \pm 7.97$ & $106.84 \pm 15.71$ & 0.71 \\
\hline Sodium $[\mathrm{mmol} / \mathrm{l}]$ & $137.83 \pm 0.27$ & $138.16 \pm 0.26$ & 0.54 \\
\hline Potassium [mmol/l] & $4.04 \pm 0.04$ & $4.18 \pm 0.05$ & 0.10 \\
\hline
\end{tabular}

BMI: body mass index; WBC: white blood cells; RBC: red blood cells; MCV: mean (red blood) cell volume; $\mathrm{MCH}$ : mean corpuscular hemoglobin; MCHC: mean corpuscular hemoglobin concentration; PLT: platelets; PDW: platelet distribution width; eGFR: estimated glomerular filtration rate; hsCRP: high-sensitivity C-reactive protein; HDL: high-density lipoprotein; LDL: low-density lipoprotein.

divided by the overall mean of all duplicated samples and then multiplied by 100, as previously described [19]. The intra-assay CV was less 6\%, and interassay was less $10 \%$.

2.7. Measurement of Prostanoids Levels. Plasma concentrations of $\mathrm{TxB}_{2}$ and 6-ketoPGF-1alpha were determined using commercial immunoassays by Enzo Life Science, strictly following manufacturer's instructions, as previously described [19].

2.8. Statistical Analysis. Data is expressed as the mean \pm SEM. The differences between two continuous parameters were assessed using the Mann-Whitney $U$ test or Student $t$-test, following the Shapiro-Wilk test and Levene test as appropriate. Proteomics data analysis was performed as described in previous section.

\section{Results}

3.1. Baseline Characteristics of Investigated Population in Subgroups. The discriminating aggregation divided the study population into two groups. The aggregation was performed using arachidonic acid ( $1 \mathrm{mM}$ working concentration) added to platelet-rich plasma in 5 minutes following its incubation with ASA at $(30 \mu \mathrm{M}$, for 5 minutes). Following the agonist application, the reaction progress was recorded for $6 \mathrm{~min}$. A complete inhibition of the aggregation by ASA was the criterion for distinguishing the AS from AR subjects. The first one constituted 36 subjects whose platelets were resistant to ASA (aspirin resistant (AR)). The second one (age and sex matched) was formed from 25 individuals that presented preserved ASA responsiveness (aspirin sensitive (AS)). The groups' characteristics are shown in Table 1. In a complete blood count, the differences between groups involved only quantitative parameters of red blood cells, hemoglobin level, hematocrit and red blood cell count that were significantly higher in AS. There were no differences observed in the qualitative measurements of erythrocyte line (MCV, $\mathrm{MCH}$, and $\mathrm{MCHC}$ ).

Regarding biochemical risk factors, significant differences (AR versus AS) concerned only fasting glucose $(83.39 \pm 1.07$ versus $88.52 \pm 2.06 \mathrm{mg} \%$, resp., $p<0.05)$ and serum creatinine $(0.96 \pm 0.02$ versus $1.11 \pm 0.03 \mathrm{mg} \%$, resp., $p<0.05)$. However, these values were maintained within normal ranges.

3.2. Platelet Function. There were no significant differences in platelet count (PLT), size (PDW), and activation level 
TABle 2: Comparison of prostanoids and markers of platelet activation in subgroups separated according to ASA response.

\begin{tabular}{lccc}
\hline- & $\begin{array}{c}\text { Decreased ASA } \\
\text { response } \\
(\text { mean } \pm \text { SEM })\end{array}$ & $\begin{array}{c}\text { Normal ASA } \\
\text { response } \\
(\text { mean } \pm \text { SEM })\end{array}$ & $p$ \\
\hline$N$ & $36-$ & $25-$ & - \\
PAI-1 $[\mathrm{ng} / \mathrm{ml}]$ & $3.11 \pm 0.31$ & $3.66 \pm 0.32$ & 0.04 \\
Sel-P $[\mathrm{ng} / \mathrm{ml}]$ & $37.45 \pm 2.10$ & $40.26 \pm 3.07$ & 0.56 \\
$\mathrm{TxB}_{2}[\mathrm{pg} / \mathrm{ml}]$ & $1557.8 \pm 410.7$ & $826.2 \pm 144.6$ & 0.28 \\
6-keto-PGF1 $\alpha[\mathrm{pg} / \mathrm{ml}]$ & $215.16 \pm 20.77$ & $187.98 \pm 18.41$ & 0.40 \\
\hline
\end{tabular}

PAI-1: plasminogen activator inhibitor-1; Sel-P: P-selectin; $\mathrm{TxB}_{2}$ : thromboxane $\mathrm{B}_{2}$, 6-keto-PGF1 $\alpha$ : 6-keto prostaglandin F1 $\alpha$.

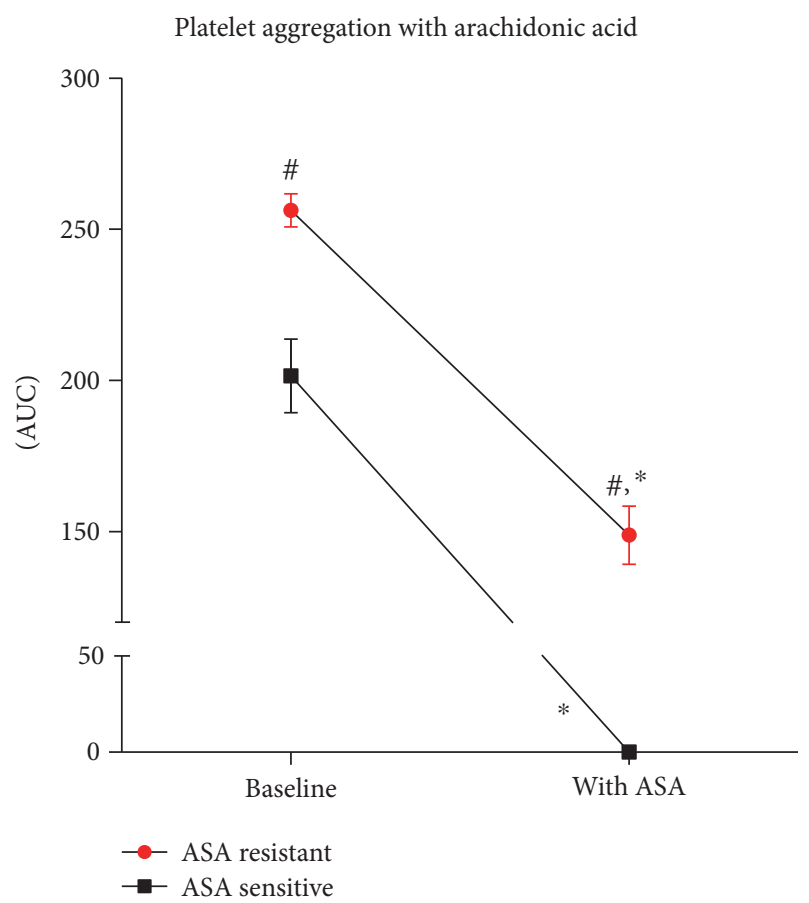

FIGURE 2: Platelet aggregation in response to arachidonic acid. Aggregations performed in platelet-rich plasma at baseline and after preincubation with ASA; AUC: area under curve of aggregation; ${ }^{*} p<0.001$ versus baseline; ${ }^{\#} p<0.001$ versus the control group.

(sP-selectin concentration) between subgroups. Nevertheless, AR subjects were characterized by lower plasminogen activator inhibitor-1 (PAI-1) concentrations ( $3.1 \pm 0.3$ versus $3.66 \pm 0.3 \mathrm{ng} / \mathrm{ml}$ in AS, resp., $p<0.05$; Table 2 ).

The AS population presented no platelet aggregation in response to arachidonic acid after PRP was preincubated with a fixed dose of aspirin. Otherwise, in AR, the aggregation was only partially blocked $(256.2 \pm 5.2$ versus $148.8 \pm$ 9.3 AU, $p<0.001)$. Furthermore, the difference between study groups was observed not only after ASA incubation $(148.8 \pm 9.5$ versus $0.08 \pm 0.08 \mathrm{AU}, p<0.001)$ but also at baseline (AA-induced aggregation without ASA, 256.2 \pm 5.2 versus $201.4 \pm 12.0 \mathrm{AU}, p<0.001$ ) (Figure 2).
3.3. Proteomic Analysis. After preliminary analytical procedures and focusing on statistically significant proteins, we identified an average of 842 proteins per patient, based on an average of 7733 peptides. The obtained results demonstrated the reproducible sample preparation, enabling thorough quantitative analysis. In the next step, the identified proteins were divided according to molecular functions and their involvement in biological processes as shown in Figures 3 and 4. Subsequent quantitative analysis revealed differentiating proteins. The differential analysis of platelet proteome between study groups showed that the only discriminatory protein, affecting the response to aspirin, is carbonic anhydrase II. Exactly the same results were obtained in different settings, both in the collagen-induced aggregates and in the nonaggregated platelets (Table 3 ).

\section{Discussion}

This is the first study to demonstrate that carbonic anhydrase II (CA II) may be linked to human aspirin resistance (AR). The CA II protein (enzyme catalogue (EC) 4.2.1.1) in platelets has been described for the first time over 30 years ago [20] and first mentioned 60 years ago [21]. It catalyzes $\mathrm{H}^{+}$ and $\mathrm{HCO}_{3}^{-}$generation from $\mathrm{CO}_{2}$ and $\mathrm{H}_{2} \mathrm{O}$ contributing to $\mathrm{pH}$ changes [22]. Nevertheless, the exact role of CA II in the platelet pathophysiology remains not fully understood. A mutation in the CA II gene results in morphological and functional changes in mouse platelets [23].

The groups in our study were homogenous allowing to assume that the only discriminator is aspirin response. We used the LC/MS technique, which is much more reliable and investigator independent than the other ones, including the 2-dimensional electrophoresis [24, 25].

One of the explanation of the CA II, ASA interaction, observed in this study may be a hypothesis that by adjusting of the cytosolic pH [22], the CA II affects the acetylating of platelet cyclooxygenase by aspirin which could in turn determine their response to the ASA.

We have shown that platelets with greater CA II concentrations not only require lower arachidonic acid concentration to overcome ASA blockage but also produce more potent baseline aggregation. We postulate that platelet CA II increases platelet sensitivity to agonists like adrenaline, thrombin, and arachidonic acid. For this reason, humans with higher platelet CA II concentration and/or activity might be at higher risk of thromboembolic events. Hence, we postulate that the importance of $\mathrm{CA}$ in cardiovascular medicine seems to be still underestimated. Interestingly, numerous drugs commonly used in cardiovascular medicine (mainly diuretics) inhibit CA. The CA II activity can be stimulated by adrenaline [26]. Furthermore, adrenaline's potential to initiate aggregation is proportional to the platelet CA II activity and may by attenuated by the CA inhibitors like chlorthalidone [27]. Acetazolamide, a selective CA II inhibitor, decreases both basal- and adrenaline-induced platelet cytosolic chloride concentration and decreases thrombin sensitivity [28] similarly to another CA inhibitor (ethoxzolamide) [29]. Such effect may be also obtained by eliminating $\mathrm{CO}_{2}$ from the platelet environment [30]. 


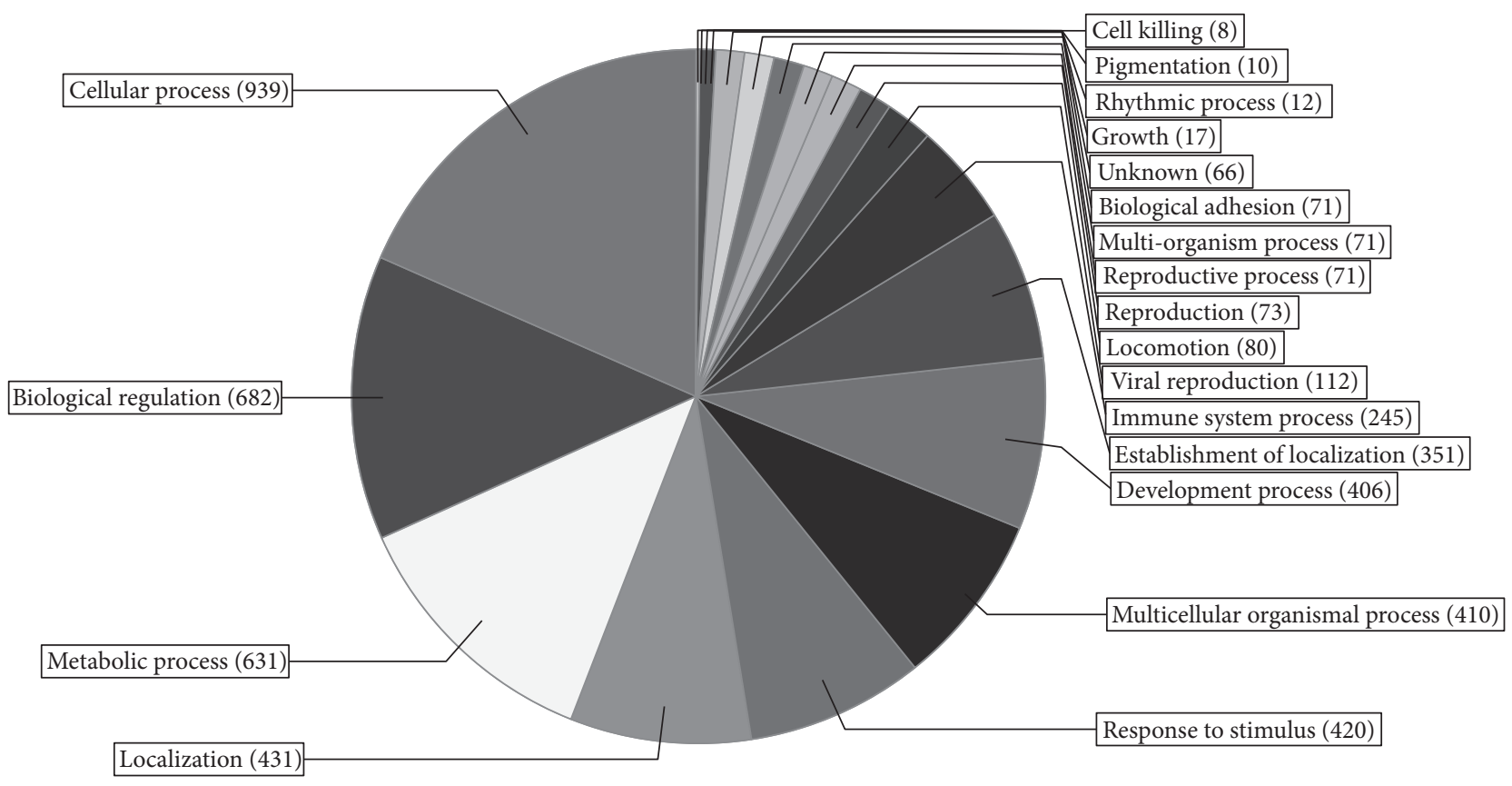

FIGURE 3: Platelet proteome organized according to involvement in biological processes of recognized proteins.

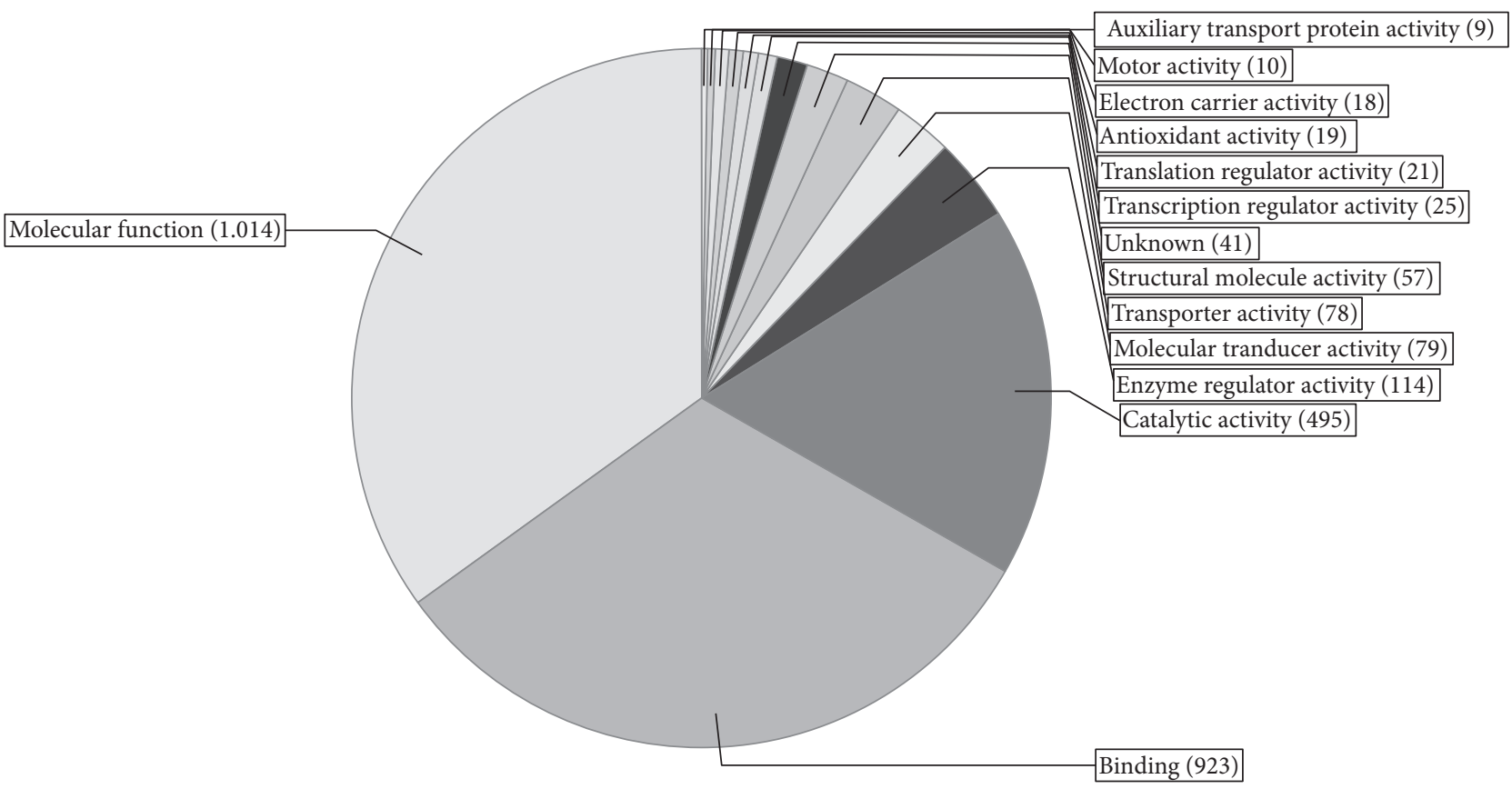

FIgURE 4: Platelet proteome organized according to molecular function of recognized proteins.

TABLE 3: Quantitative LC/MS analysis of proteomes of platelets sensitive versus resistant to ASA (only discriminatory proteins are specified).

\begin{tabular}{lcccccc}
\hline Material & Protein & $q$ value & Ratio & Fold change & Number of peptides & Protein name \\
\hline $\begin{array}{l}\text { Collagen-induced } \\
\text { aggregation pellets }\end{array}$ & P00918 & 0.00213 & 0.67 & 1.49 & 18 & Carbonic anhydrase 2 OS = Homo sapiens \\
Inactivated platelets & P00918 & 0.00106 & 0.69 & 1.44 & 19 & Carbonic anhydrase 2 OS = Homo sapiens \\
\hline
\end{tabular}


What is more, the authors of a recent systemic review confirmed that thiazide-like diuretics have a superiority in reducing cardiovascular events over thiazide-type ones independently of lowering the blood pressure [31], which might be due to their activity against CA II and subsequent platelet aggregation [27].

Our results regarding sex distribution among AR population confirm the data published by other groups [32], and it should be verified if platelet CA II presents different sexdependent activities. Lower red blood cells (RBC), hematocrite, and the hemoglobin levels in the AR population are accompanied by higher platelet CA II content. Anemia caused by iron deficiency has been demonstrated to be a risk factor for ischemic stroke due to reactive thrombocytosis, which might be a compensatory mechanism providing sufficient CA activity, normally substantially maintained by RBCs [33]. Platelet CA II might cooperate with the CA in RBCs in maintaining the acid-based blood balance. In our study, a thrombocytosis was not well marked, but increased CA II expression might induce differences in platelet function.

\section{Conclusions}

Carbonic anhydrase II (CA II) is a modulator of platelet function. Increased activity and/or concentration of CA II in platelets should be rated as a new independent risk factor for aspirin resistance and thus for thromboembolic events. There may be a need to use the drugs inhibiting CA in clinical setting more often nowadays, especially in patients with increased platelet activity/amount of CA II.

\section{Conflicts of Interest}

The authors declare that there is no conflict of interest regarding the publication of this article.

\section{Acknowledgments}

This study was funded by the Polish Ministry of Science and Higher Education (Grant Iuventus Plus no. IP 2011-010471) obtained by Adrian Doroszko.

\section{References}

[1] Writing Group Members, D. Mozaffarian, E. J. Benjamin et al., "Heart disease and stroke statistics-2016 update: a report from the American Heart Association," Circulation, vol. 133, pp. e38-e360, 2016.

[2] G. Du, Q. Lin, and J. Wang, "A brief review on the mechanisms of aspirin resistance," International Journal of Cardiology, vol. 220, pp. 21-26, 2016.

[3] U. S. Tantry, M. Gesheff, F. Liu, K. P. Bliden, and P. A. Gurbel, "Resistance to antiplatelet drugs: what progress has been made?," Expert Opinion on Pharmacotherapy, vol. 15, pp. 2553-2564, 2014.

[4] C. N. Floyd and A. Ferro, "Mechanisms of aspirin resistance," Pharmacology \& Therapeutics, vol. 141, pp. 69-78, 2014.

[5] M. D. Mijajlovic, O. Shulga, S. Bloch, N. Covickovic-Sternic, V. Aleksic, and N. M. Bornstein, "Clinical consequences of aspirin and clopidogrel resistance: an overview," Acta Neurologica Scandinavica, vol. 128, pp. 213-219, 2013.

[6] E. G. Kovács, E. Katona, Z. Bereczky et al., "New direct and indirect methods for the detection of cyclooxygenase 1 acetylation by aspirin; the lack of aspirin resistance among healthy individuals," Thrombosis Research, vol. 131, pp. 320-324, 2013.

[7] N. Homoródi, E. G. Kovács, S. Leé et al., "The lack of aspirin resistance in patients with coronary artery disease," Journal of Translational Medicine, vol. 14, p. 74, 2016.

[8] V. Evangelista, S. Manarini, A. Di Santo et al., "De novo synthesis of cyclooxygenase-1 counteracts the suppression of platelet thromboxane biosynthesis by aspirin," Circulation Research, vol. 98, pp. 593-595, 2006.

[9] D. Voora, T. L. Ortel, J. E. Lucas, J. T. Chi, R. C. Becker, and G. S. Ginsburg, "Time-dependent changes in non-COX-1dependent platelet function with daily aspirin therapy," Journal of Thrombosis and Thrombolysis, vol. 33, pp. 246257, 2012.

[10] D. Voora, D. Cyr, J. Lucas et al., “Aspirin exposure reveals novel genes associated with platelet function and cardiovascular events," Journal of the American College of Cardiology, vol. 62, pp. 1267-1276, 2013.

[11] I. Massimi, R. Guerriero, L. V. Lotti et al., “Aspirin influences megakaryocytic gene expression leading to up-regulation of multidrug resistance protein-4 in human platelets," British Journal of Clinical Pharmacology, vol. 78, pp. 1343-1353, 2014.

[12] I. Massimi, A. Ciuffetta, F. Temperilli et al., "Multidrug resistance protein- 4 influences aspirin toxicity in human cell line," Mediators of Inflammation, vol. 2015, Article ID 607957, 9 pages, 2015.

[13] I. Massimi, L. V. Lotti, F. Temperilli et al., "Enhanced platelet MRP4 expression and correlation with platelet function in patients under chronic aspirin treatment," Thrombosis and Haemostasis, vol. 116, pp. 1100-1110, 2016.

[14] F. Temperilli, M. Di Franco, I. Massimi et al., "Nonsteroidal anti-inflammatory drugs in-vitro and in-vivo treatment and multidrug resistance protein 4 expression in human platelets," Vascular Pharmacology, vol. 76, pp. 11-17, 2016.

[15] C. N. Floyd, T. Goodman, S. Becker et al., "Increased platelet expression of glycoprotein IIIa following aspirin treatment in aspirin-resistant but not aspirin-sensitive subjects," British Journal of Clinical Pharmacology, vol. 78, pp. 320-328, 2014.

[16] M. Mikula, P. Gaj, K. Dzwonek et al., "Comprehensive analysis of the palindromic motif TCTCGCGAGA: a regulatory element of the HNRNPK promoter," DNA Research, vol. 17, pp. 245-260, 2010.

[17] M. Bakun, G. Senatorski, T. Rubel et al., "Urine proteomes of healthy aging humans reveal extracellular matrix (ECM) alterations and immune system dysfunction," Age, vol. 36, pp. 299-311, 2014.

[18] A. Malinowska, M. Kistowski, M. Bakun et al., "Diffprotsoftware for non-parametric statistical analysis of differential proteomics data," Journal of Proteomics, vol. 75, pp. 4062 4073, 2012.

[19] A. Doroszko, E. Szahidewicz-Krupska, A. Janus et al., "Endothelial dysfunction in young healthy men is associated with aspirin resistance," Vascular Pharmacology, vol. 67-69, pp. 30-37, 2015.

[20] W. Siffert and G. Gros, "Carbonic anhydrase in human platelets,” The Biochemical Journal, vol. 217, pp. 727-730, 1984. 
[21] F. Belloni and R. Turpini, "Presence of carbonic anhydrase in human platelets," Haematologica, vol. 42, pp. 217-225, 1957.

[22] H. Vaitkevicius, I. Turner, A. Spalding, and W. Lockette, "Chloride increases adrenergic receptor-mediated platelet and vascular responses," American Journal of Hypertension, vol. 15, pp. 492-498, 2002.

[23] E. K. Novak, H. O. Sweet, M. Prochazka et al., "Cocoa: a new mouse model for platelet storage pool deficiency," British Journal of Haematology, vol. 69, pp. 371-378, 1988.

[24] I. A. Brewis and P. Brennan, "Proteomics technologies for the global identification and quantification of proteins," Advances in Protein Chemistry and Structural Biology, vol. 80, pp. 1-44, 2010.

[25] J. Peng and S. P. Gygi, "Proteomics: the move to mixtures," Journal of Mass Spectrometry, vol. 36, pp. 1083-1091, 2001.

[26] C. Temperini, A. Scozzafava, and C. T. Supuran, "Carbonic anhydrase activation and the drug design," Current Pharmaceutical Design, vol. 14, pp. 708-715, 2008.

[27] R. Woodman, C. Brown, and W. Lockette, "Chlorthalidone decreases platelet aggregation and vascular permeability and promotes angiogenesis," Hypertension, vol. 56, pp. 463-470, 2010.

[28] A. Spalding, H. Vaitkevicius, S. Dill, S. MacKenzie, A. Schmaier, and W. Lockette, "Mechanism of epinephrine-induced platelet aggregation," Hypertension, vol. 31, pp. 603-607, 1998.

[29] W. Siffert, G. Fox, and G. Gros, "Carbonic anhydrase in human platelets: effects of carbonic anhydrase inhibition on platelet aggregation," Annals of the New York Academy of Sciences, vol. 429, pp. 207-209, 1984.

[30] W. Siffert, G. Fox, and G. Gros, "The effect of carbonic anhydrase inhibition on the velocity of thrombin-stimulated platelet aggregation under physiological conditions," Biochemical and Biophysical Research Communications, vol. 121, pp. 266-270, 1984.

[31] R. H. Olde Engberink, W. J. Frenkel, B. van den Bogaard, L. M. Brewster, L. Vogt, and B. J. van den Born, "Effects of thiazidetype and thiazide-like diuretics on cardiovascular events and mortality: systematic review and meta-analysis," Hypertension, vol. 65, pp. 1033-1040, 2015.

[32] H. Shen, W. Herzog, M. Drolet et al., "Aspirin resistance in healthy drug-naive men versus women (from the heredity and phenotype intervention heart study)," The American Journal of Cardiology, vol. 104, pp. 606-612, 2009.

[33] Y. L. Chang, S. H. Hung, W. Ling, H. C. Lin, H. C. Li, and S. D. Chung, "Association between ischemic stroke and iron-deficiency anemia: a population-based study," PLoS One, vol. 8, article e82952, 2013. 


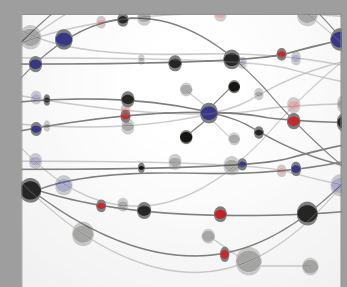

The Scientific World Journal
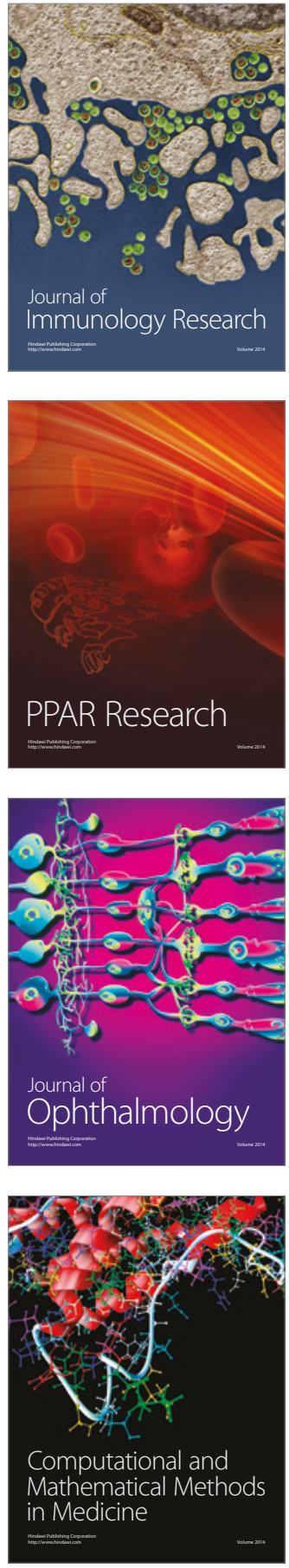

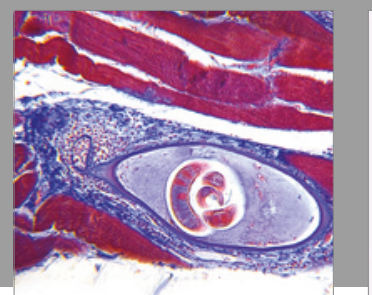

Gastroenterology Research and Practice
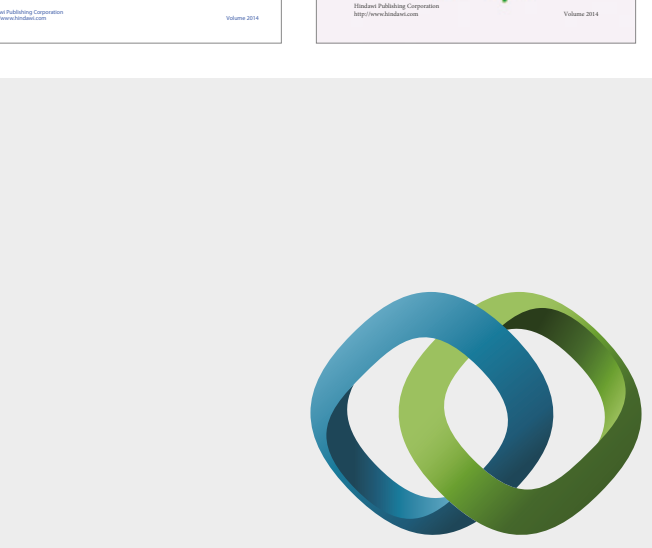

\section{Hindawi}

Submit your manuscripts at

https://www.hindawi.com
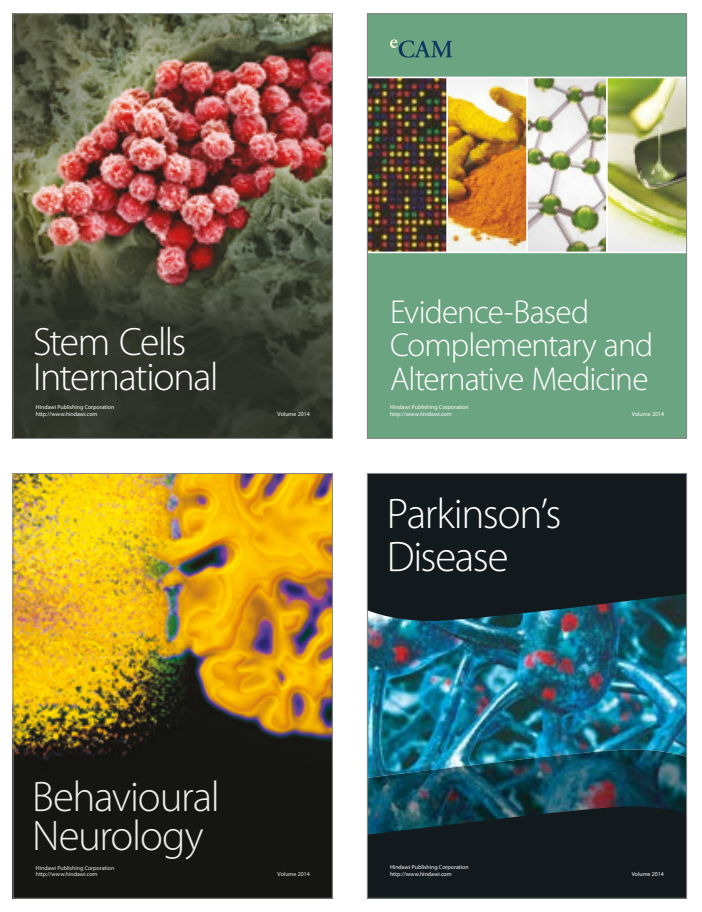
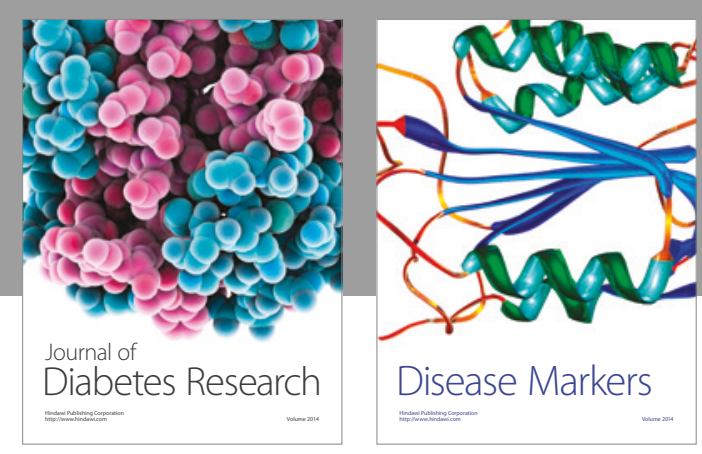

Disease Markers
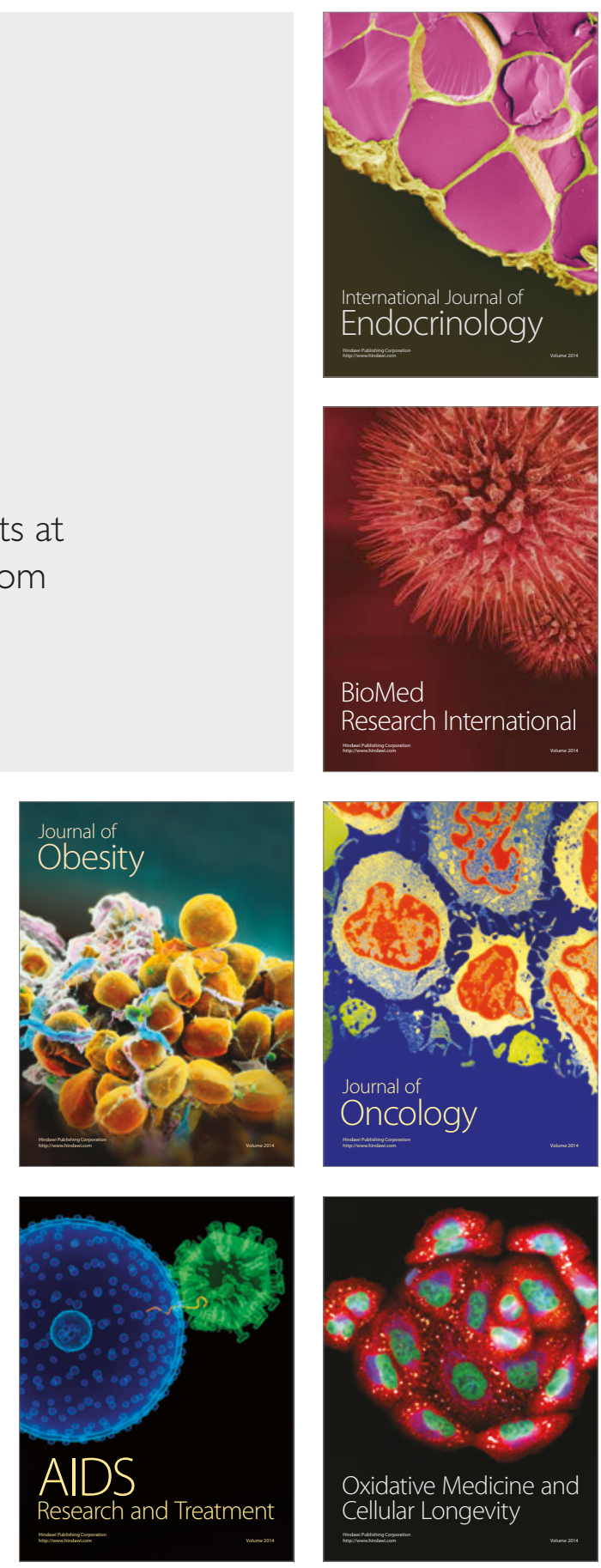